\title{
Necesidad y utopía en la modernidad temprana y en la conquista de Chile $^{1}$
}

\author{
Need and Utopia in early \\ Modernity and the conquest of Chile \\ Luz Martínez Canabal" \\ aAcadémica, Facultad de Filosofía y Humanidades, Universidad de Chile \\ $\searrow$ luzmartine@gmail.com
}

\begin{abstract}
RESUMEN
Este trabajo, propone que la "noticia del nuevo mundo" influyó decisivamente en la migración del asunto de la necesidad judeocristiano desde lo teológico hacia el ámbito de la filosofía y la política del siglo XVI, y de ahí en adelante. La reflexión entorno de estos asuntos incluye el comentario de varios tipos textuales desde el siglo XVI hasta el siglo XX: cartas de descubrimiento, tratados filosóficos, textos del ámbito del psicoanálisis y poemas escritos en el Reino de Chile.
\end{abstract}

PALABRAS CLAVE: utopía, descubrimiento, necesidad, malestar, Reino de Chile, modernidad, psicoanálisis.

\begin{abstract}
This work proposes that the "news of the New World" had a decisive influence on the migration of the subject of Judeo-Christian need from the theological sphere to that of philosophy and 16th-century politics, from that period on. The reflection on these matters includes commentary from several kinds of texts from the 16th century to the 20th: letters of discovery, philosophical treatments, poems written in kingdom of Chile, even texts from the field of psychoanalysis.
\end{abstract}

KEY WORDS: utopia, discovery, need, discontent, kingdom of Chile, modernity, psychoanalysis.

1 Este trabajo se realizó en el contexto del Proyecto de Investigación Regular 1171070 financiado por FONDECYT. Recibido: 15 de mayo de 2018

Aceptado: 19 de junio de 2018 


\section{MARTÍNEZ}

\section{INTRODUCCIÓN}

La existencia de sociedades no organizadas alrededor de la necesidad ha constituido una problemática que la cosmovisión judeo-cristiana no logra manejar muy bien incluso hasta hoy, pues se imbrica contradictoriamente con su relato de origen y con la historia del hombre arrojado del Jardín del Edén a las penurias y carencias sin fin del mundo, y hasta el fin del mundo. De tal manera que para esa Historia mito teológica, expandida desde finales del siglo XV a escala planetaria por los reinos católicos de Portugal y España², la necesidad no es, por decirlo de alguna manera, un acontecimiento o un hecho eventual a enfrentar y solucionar, sino un elemento constitutivo de la condición humana que la protagoniza y la padece, así como una marca indeleble de la ira divina sobre su pueblo y sobre la tierra misma, convertida desde 1492 en el escenario global y moderno ${ }^{3}$ de un peregrinar doloroso.

Desde la modernidad temprana el relato teológico del castigo pareciera haberse debilitado en algunos ámbitos, en la filosofía y la ciencia especialmente ${ }^{4}$, sin que por ello se haya minimizado en un ápice el asunto de la necesidad, no al menos en la cosmovisión de la cual estamos hablando, ni en los discursos que esta produce. Advertido aquello, este trabajo propone que "la noticia del nuevo mundo" y sus sociedades tensionó de manera inédita el asunto de la necesidad e influyó notoriamente en su desplazamiento a otros ámbitos culturales, donde tomó nuevas formas discursivas y produjo transformaciones en la conciencia, que se pueden reconocer ya como propiamente modernas. Por ejemplo, la que inaugura Utopía (1516) de Tomás Moro $^{5}$ en las puertas del pensamiento político moderno ${ }^{6}$ y durante el proceso de occidentalización sufrido por las culturas prehispánicas y precatólicas de América. Para observar la migración del relato bíblico de la necesidad al ámbito profano de la cultura y su expansión histórica, revisaremos distintos tipos de textos y

2 Si bien se han propuesto distintas fechas para el inicio de la expansión de estos reinos y el proceso puede coincidir con la lucha contra los moros y el inicio de la Reconquista, en este trabajo se asume que aquello comienza en 1492, con el viaje de Cristóbal Colón y con la conquista material y espiritual de los "nuevos mundos". Como documento de esa expansión global o planetaria, se remite al Planisferio o Carta de Cantino de 1502.

3 Gruzinski, Serge. Las cuatro partes del mundo. Historia de una mundialización. México: Fondo de Cultura Económica, 2010.

4 La relación entre modernidad y ciencia es marcada por el Premio Novel de física (1979) Steven Weinberg de la siguiente manera: “... estoy convencido de que la revolución científica significó una auténtica ruptura en la historia intelectual, y lo considero desde la perspectiva de un científico contemporáneo. Con las pocas y brillantes excepciones griegas, la ciencia anterior al siglo XVI me parece muy distinta de la que yo mismo practico o veo en el trabajo de mis colegas. Antes de la revolución científica, la ciencia estaba impregnada de religión, de lo que llamamos filosofía y todavía no había resuelto su relación con las matemáticas. En física y astronomía, después del siglo XVII ya me siento cómodo. Reconozco algo muy semejante a la ciencia de mi propia época..." Weinberg, Steven. Explicar el mundo. Buenos Aires: Taurus, 2016. p. 156.

Ese camino que lleva el pensamiento de Dios a la Ley natural y esa "auténtica ruptura en la historia intelectual" -observada por demás en todos los ámbitos culturales- es la que notifica la emergencia de la modernidad temprana de la que estamos hablando.

5 De aquí en adelante todas las citas de Utopía son tomadas de la presente edición: Hopenhayn, M. (2005) Utopías del Renacimiento: Moro/Campanella/Bacon. México: Fondo de Cultura Económica.

6 Utopía de Tomás Moro y El Príncipe de Nicolás Maquiavelo, entre otras, inauguran el pensamiento político moderno. La relación entre estas dos obras la abordaremos más adelante. 
documentos: cartas, tratados políticos, filosóficos y poemas producidos en el siglo XVI, hasta ensayos psicoanalíticos producidos en el siglo XX, especialmente aquellos en que vemos el anudamiento entre conciencia, utopía y necesidad que recorre y amalgama el proceso de occidentalización americana. Finalmente, revisaremos la trabazón poética de estos asuntos en algunos textos producidos durante la conquista del Reino de Chile.

Necesidad y malestar de la conciencia moderna

Cuando se han cumplido quinientos años de la aparición del discurso utópico moderno, observamos que la cuestión de la necesidad -y su derivación en las distintas formas de la infelicidad-, reaparece una y otra vez asociada al desarrollo de la historia y a la configuración social. En este sentido, es significativo que la representación de la necesidad en nuestra contemporaneidad cercana incorpore referencias más o menos directas o distantes a la conquista de los "nuevos mundos", y que esa representación construya una oposición entre "primitivos" y "civilizados" para caracterizar, de algún modo, lo que llamamos conciencia moderna. De ahí que resulte importante preguntarse por el impacto que tuvo la "noticia del descubrimiento" en la subjetividad del siglo XVI y cómo ese impacto irradia hasta la subjetividad que nos es próxima. Para respondernos aquello, vamos a observar el pensamiento de Rafael Hitlodeo, el protagonista de Utopía, a la luz de otra de las grandes reflexiones contemporáneas sobre la cuestión de la necesidad, el pensamiento de Sigmund Freud.

Una síntesis notable de todo lo anterior se encuentra en el influyente ensayo de Freud (1930) titulado El malestar en la cultura ${ }^{7}$, que si bien comienza como una discusión sobre el sentimiento religioso de los seres humanos, a muy poco andar resulta ser una reflexión psicoanalítica, científica por supuesto, sobre el sentimiento de infelicidad experimentado por los hombres que pertenecen al mismo universo cultural de su autor. En este contexto, el inventor de la psiquis contemporánea se hace la siguiente pregunta:

¿Por qué caminos han llegado tantos hombres a esta extraña actitud de hostilidad contra la cultura? Creo que un profundo y antiguo disconformismo con el respectivo estado cultural constituyó el terreno en que en determinadas circunstancias históricas hicieron germinar la condenación de aquella (p. 31)

Entre otras causas de la desdicha social, Freud (2006) se responde lo siguiente:

El penúltimo motivo surgió cuando, al extenderse los viajes de exploración se entabló contacto con razas y pueblos primitivos. Los europeos, observando superficialmente e interpretando de manera equívoca sus usos y costumbres, imaginaron que esos

Todas las citas a este ensayo son tomadas de la presente edición: Freud, S. (2006). El malestar en la cultura. España: Alianza Editorial. **** reediciones. Michel De Certeau ha puesto en relieve el interés de Freud por los siglos XVI y XVII. De Certeau, M (2003). Historia y Psicoanálisis. México: Universidad Iberoamericana. 


\section{MARTÍNEZ}

pueblos llevaban una vida simple, modesta y feliz, que debía parecer inalcanzable a los exploradores de nivel cultural más elevado. La experiencia ulterior ha rectificado muchos de estos juicios, pues en múltiples casos se había atribuido tal facilitación de la vida a la falta de complicadas exigencias culturales, cuando en verdad obedecía a la generosidad de la Naturaleza y a la cómoda satisfacción de las necesidades elementales (p. 32).

Dejando de lado el eurocentrismo evidente de esta respuesta, de ella nos interesan en principio dos cosas. La primera es que para hablar de la desdicha del sujeto europeo judeocristiano moderno, Freud repone el relato de la empresa de conquista global emprendida por la península ibérica a finales del siglo XVI, al mismo tiempo que presenta ese proceso histórico como una escena edénica de contacto que hay que desmentir científicamente. Lo segundo es que Freud adjudica la desdicha del "sujeto civilizado" a una suerte de añoranza por una forma de vida feliz que los "primitivos" sí tendrían y los europeos no, de tal modo que en esta "determinada circunstancia histórica", la comparación con el otro desata una proyección reflexiva (o de efecto bumerán) en virtud de la cual los "sujetos civilizados" no ven la felicidad del "primitivo" como un hecho objetivo, sino que ven reflejada en él su propia infelicidad, acrecentándose con ello la hostilidad que sienten hacia su propia cultura.

Desmitificado el encantamiento de la "escena primitiva" por la observación juiciosa, Freud concluye categóricamente que ese estado de felicidad no tiene una causa cultural, social o espiritual de ningún tipo; no tiene ninguna relación con "los usos y costumbres", es decir, con la humanidad del "primitivo", sino con la Naturaleza que este habita. En la lógica freudiana, es la prodigalidad de la Naturaleza la que proporciona al primitivo esa felicidad "inalcanzable" a ojos de los europeos, de modo que es la condición bondadosa de esa Naturaleza, frente a otra, por oposición, no bondadosa, la que determina la diferencia anímica entre los unos y los otros, entre "primitivos" y "civilizados", "felices" e "infelices".

La conclusión naturalista de Freud nos permite revisar desde otra perspectiva el trasfondo religioso de la necesidad que ya señalamos, pero que es necesario reconsiderar para ver cómo en el inicio de la nueva conformación global el "nuevo mundo" se opone al "viejo mundo" en este punto. De un lado, están la Naturaleza generosa y el sujeto feliz, libres ambos de inferir o padecer la tiranía de la necesidad. En el lado opuesto se encuentran la Naturaleza que produce sufrimiento ${ }^{8}$ y el sujeto desdichado que lo padece y reproduce: el sujeto hostil a su cultura. Esta última unidad corresponde, como sabemos, al marco teológico judeocristiano, al hombre y la naturaleza malditos por Yahvé, al desarrollo histórico cultural post expulsión del Paraíso Terrenal y a lo que podemos llamar "la geografía de la desdicha". La primera unidad, compuesta por la Naturaleza y el hombre primitivos, es absolutamente ajena al relato teológico judeocristiano, a la "geografía de la desdicha" que le corresponde ${ }^{9} \mathrm{y}$

8 "Ya hemos respondido al señalar las tres fuentes del humano sufrimiento: la supremacía de la Naturaleza..." (Freud, 2006, p. 30).

9 "Y al hombre dijo: Por cuanto obedeciste a la voz de la mujer, y comiste del árbol de que te mandé diciendo: No comerás de él; maldita será la tierra por tu causa; con dolor comerás de ella todos los días de tu vida” (Génesis 3, 17). 
al escenario histórico de la naturaleza percibida como fuente de sufrimiento.

Ciertamente el análisis de Freud resulta ajustadísimo si lo proyectamos sobre la conciencia del personaje principal de una de las primeras y más influyentes obras de la modernidad, en la cual la expansión europea es un hecho significativo, Utopía, de Moro. Pues, leída a la luz de Freud ¿no es Utopía una de las obras más hostiles a la cultura europea católica que se han escrito? ¿No es Rafael Hitlodeo, su protagonista, aquel explorador civilizado, de humor oscuro, de espíritu angustiado, que, tras viajar a los "nuevos mundos" con Américo Vespucio ${ }^{10}$, se transforma en el mayor antagonista de su propia cultura? ¿Acaso su crítica no está movilizada por un mecanismo proyectivo de la infelicidad? ¿No representa ejemplarmente el estado de malestar de la conciencia moderna? Ciertamente así es y bajo este prisma bien parece que la conciencia desdichada de Hitlodeo y su irritación cultural enlazan la obra de Moro, el "nuevo mundo" y el ensayo de Freud a través de los siglos que componen la modernidad.

\section{Utopía y Nuevo Mundo}

Como se ha dicho tantas veces y en tantas direcciones ${ }^{11}$, Utopía articula su discurso a "la noticia del descubrimiento" y a una serie de fenómenos culturales y a espacios naturales extra-europeos representados en la famosa carta Nuevo Mundo, escrita o atribuida a Américo Vespucio, más o menos en 1503. En ese documento, el navegante florentino describió una serie de usos y costumbres observados en algunas comunidades pre-hispánicas de la actual Suramérica, cuyas características pueden ser enumeradas grosso modo de la siguiente manera. Ausencia en ellas de un rey y del lazo de vasallaje asociado a esta figura centralizadora del poder; ausencia de la idea de mercancía y del valor monetario del oro; inapetencia del territorio ajeno, inexistencia de la propiedad privada, libertad de culto y lo que diríamos en palabras de hoy, "libertad sexual" de mujeres y hombres. Todo lo anterior se enmarca en el régimen comunitario de los bienes proclamado después por Hitlodeo en Utopía como la fuente incuestionable de la felicidad social (mal interpretada según Freud) a la que deben aspirar las atribuladas sociedades europeas. El párrafo que caracteriza mejor todo aquello es el siguiente:

No tienen paños de lana ni de lino ni aún de bombasí porque nada de ello necesitan. Ni tampoco tienen bienes propios, pero todas las cosas son comunes. Viven juntos sin rey, sin autoridad y cada uno es señor de sí mismo. Toman tantas mujeres cuantas quieren, y el hijo se mezcla con la madre, y el hermano con la hermana, y el primo

10 Así dice Pedro Egidio de Rafael Hitlodeo, “...en su deseo de conocer nuevas tierras, juntóse a Américo Vespucio, del que fue compañero inseparable en los tres últimos de los cuatros viajes que andan en manos de todos; mas no regresó con él en el postrero, sino que solicitó y obtuvo de Américo, casi por la fuerza, ser uno de los veinticuatro que se quedaron en una ciudadela situada en los confines de alcanzados en dicho viaje" (p. 9).

11 Pastor, B. (1999). El jardín y el peregrino. México: Coordinación de difusión cultural UNAM. 


\section{MARTÍNEZ}

con la prima y el viandante con cualquiera que se encuentra. Cada vez que quieren deshacen el matrimonio y en esto ninguno observa orden. Además no tienen ninguna iglesia, ni tienen ninguna ley ni siquiera son idólatras. ¿Qué otra cosa diré? Viven según la naturaleza, y pueden llamarse más justamente epicúreos que estoicos. No son entre ellos comerciantes ni mercan cosa alguna $(73)^{12}$.

No obstante Vespucio propone esta información como "novísima noticia”, algunas de las características que singularizan una sociedad que vive epicúreamente según la ley natural ya han sido introducidas en Europa una década antes por las Cartas (1493) de Cristóbal Colón a Luis de Santángel o al papa Alejandro VI, solo por nombrar dos textos tan famosos y difundidos entre monarcas y vasallos como Mundus Novus (1504). De tal manera que a la escritura de Mundus Novus y de Utopía, la gran divulgación de los documentos colombinos ${ }^{13}$ ya había regado una serie de ideas sobre la abundancia y epicureísmo del "nuevo mundo" que comenzaron a tensionar de manera inédita la cuestión de la necesidad al interior de la Europa católica. Una de esas ideas, conocida como la "maravilla" o "lo maravilloso", comienza pregonando la bondad de las nuevas tierras y termina afirmando en ellas la existencia del Paraíso Terrenal ${ }^{14}$. Las otras inquietantes ideas que acompañaron esa conmoción histórica son de orden político y económico, relacionadas todas con la abundancia vegetal y mineral de una nueva naturaleza inexplicablemente edénica, que aparece como una promesa benigna y concreta ante la carencia.

En resumen, el almirante informa a las autoridades político-religiosas que en las inmediaciones paradisiacas existían sociedades que no conocían el hierro, no basaban el intercambio de bienes en el valor del oro, las piedras preciosas o la plata. Tampoco tenían una superestructura religiosa que regulara la vida de los sujetos, ni un rey que poseyera esos extensos territorios o sometiera al vasallaje esa multitud de gentes en su totalidad. A la "noticia del descubrimiento", agregaba Colón una serie de comentarios que apuntaban a algo totalmente desconocido en la Europa de la época: esto es, la existencia de sociedades no organizadas alrededor de la privación y la carencia, compuestas por gentes mansas que no padecían egoísmo, ni siquiera con los extranjeros europeos, a quienes ofrecían generosamente sus bienes ${ }^{15}$. Esta generosidad llega al escándalo cuando entregan sin más el oro que poseen, metal al que demuestran el mismo desapego que los habitantes de Utopía. En este recuento, las descripciones de Colón y Vespucio son cercanísimas, casi idénticas, se refuerzan mutuamente y coinciden en lo mismo: como quiera que se imagine el Jardín del Edén, sin lugar a dudas debe parecerse a las regiones que ellos visitaron en sus viajes.

12 Vespucio A. (2015). El Nuevo Mundo. Los viajes de Amérigo Vespucci (1497-1504). Traducción, introducción y notas de Jean-Paul Duviols. Estados Unidos Stockcero. Pp. 71-81.

13 Desde 1493 a 1497 la carta de Colón a Luis de Santángel tuvo nueve ediciones en latín en diferentes partes de Europa, cinco ediciones en italiano, dos en castellano, una en alemán. De ahí en adelante se sigue publicando.

14 Tercer viaje de Colón.

15 Ver el relato del primer viaje en: Columbus, C. (1982). Textos y documentos completos. Relaciones de viajes, cartas y memoriales. Edición, prólogo y notas de Consuelo Varela. Madrid: Alianza Editorial. 
La coincidencia entre los textos más famosos, reimpresos y difundidos en Europa entre finales del siglo XV y primeras décadas del XVI, permite pensar que las sociedades del viejo continente fueron impactadas por un relato que afirmaba la condición de posibilidad de modelos sociales ajenos y contrarios a los fundamentos y predicamentos de la desdichada historia europea judeocristiana: “...maldita será la tierra por tu causa; con dolor comerás de ella todos los días de tu vida”, etc. Asimismo, que tal impacto tuvo características inéditas y consecuencias inusitadas, pues, como nunca antes, esa afirmación se sostenía sobre la existencia empírica de sociedades que a su manera, por otras vías, no occidentales, habían logrado aquello que para el modelo europeo había sido hasta ese momento una elucubración sin condición de posibilidad: un postulado filosófico, mesiánico o religioso, regulado básicamente por distintos dispositivos de desplazamiento y proyección sobre el inmensurable telón de fondo de las entelequias y del más allá. Como dijimos al inicio, el relato que irrumpe y perturba esa proyección es "la noticia del descubrimiento", que de repente vino a sostener la existencia concreta de una sociedad compuesta por seres libres, en donde cada quien es "señor de sí mismo", como afirmaba Vespucio, y en la cual la libertad no es sinónimo de codicia ni obstáculo para que florezca el régimen de la comunidad de los bienes, como afirmará posteriormente el discurso político de Moro.

Este es el contexto histórico de producción de Utopía y en relación con él la escenificación de su discurso en la naturaleza y en las sociedades extra-europeas cobra un valor muy distinto del meramente ficcional-narrativo o del "detalle exótico" que se puede pasar por alto. En esta dirección, señalemos primero que la contextualización del discurso utópico en los viajes de descubrimiento hace de él uno de los primeros discursos políticos globales modernos. Luego, que Utopía es la primera sociedad perfecta de esa globalidad. Por último, que está emplazada precisamente en las inmediaciones edénicas -o que solo pueden ser leídas así por el europeo cristiano en tránsito hacia la modernidad- a las cuales dicen haber llegado Colón y Vespucio en este nuevo mundo real ${ }^{16}$. En este escenario la transferencia simbólica entre un espacio y otro, entre Jardín del Edén y mundo, fue inevitable y compuso necesariamente un empalme (espurio) entre lo histórico imperfecto y lo trascendente perfecto; entre lo que está en la tierra y lo que está fuera de ella en la idealidad filosófica o en el más allá de Dios. De tal manera que la imaginación de la nueva geografía del orbe incorpora una relación de contigüidad que enlaza tres espacios intrínsecamente distintos y disyuntivos, el nuevo mundo, el Edén y el espacio metafísico, y los hace localizables en las nuevas coordenadas geográficas de la expansión europea. En este sentido, como en muchos otros, el contexto de producción intelectual europeo del siglo XVI es distinto a todos los que le anteceden y enfrenta tensiones nuevas en sus cruces y formulaciones. Por ejemplo, las que se articulan entre lo antiguo y lo nuevo: Modelos sociales desplazados/Modelos sociales emplazados; proyecto social metafísico/proyecto social empírico; hombres libres/vasallos; propiedad privada/comunidad de los bienes.

16 La ecúmene bíblica tripartita precolombina y prevespuciana era, como sabemos, irreal. 


\section{MARTÍNEZ}

Al inicio dijimos que Utopía es uno de los primeros desplazamientos discursivos del asunto de la necesidad desde la condena divina hacia el campo de lo descifrable por la razón política y filosófica. Sin embargo, para poner en perspectiva su anclaje histórico en la "noticia del nuevo mundo" y en la escenificación americana, es menester detenerse en algunos aspectos compositivos de la obra. Puntualmente, en las distintas etapas del viaje, relacionadas específicamente con la construcción del discurso político-filosófico que la caracteriza.

Del primer trayecto del viaje se nos dice poco o nada, solo sabemos que finaliza cuando Rafael Hitlodeo decide abandonar la expedición de Vespucio para quedarse con otros marineros en las nuevas tierras, de tal manera que si quisiéramos saber qué le sucedió a Hitlodeo en ese periodo, tendríamos que leer las cartas del navegante florentino. La decisión de permanecer ahí, junto a "los primitivos", inaugura otro trayecto, cuya otredad se inicia con ese cambio de rumbo, pues a partir de ahí a el discurso de la obra se diferencia del relato de expedición para transformarse en el discurso político-filosófico de la trascendencia que conocemos. El hecho es que el verdadero viaje hacia Utopía comienza cuando Rafael deja atrás las naves europeas y toma un tipo de nave distinto y desconocido, una canoa precolombina precisamente, gobernada por sujetos autóctonos, no europeos, no católicos, no grecolatinos: primitivos, según Freud. Guiado por ellos Rafael emprende un rumbo hacia lo desconocido, y lo desconocido es, en este caso, el conocimiento de una sociedad y mundo mejores.

En este punto es casi innecesario insistir en que existen pocas cosas tan cargadas de connotaciones simbólicas que la imagen de la nave en la cultura occidental, y más aún cuando conduce al sujeto al conocimiento de una realidad nueva, a una revelación. No obstante es importante detenerse un poco más en la disyunción representada por el galeón y la canoa y ponerla en la perspectiva del pensamiento político filosófico del siglo XVI europeo. En Utopía, la tradición que busca perpetuarse, versus las posibilidades emancipadoras que ofrece "lo nuevo", configuran dos hilos que tensan toda la argumentación del la obra ${ }^{17}$ y su diálogo con el medio. Del lado de la tradición se encuentra la sociedad injusta, intracolonial ${ }^{18}$, gobernada por

17 "Pero, si alguno..., adujese que ha leído como realizado en otros tiempos, o que vio ejecutar en otros lugares, los que le oyen obran como si peligrase toda su reputación de sabios, y se le fuese a considerar en adelante como tontos de remate, a menos que logren descubrir algo censurable en las ideas extrañas. Si no encuentran otros argumentos se refugian en lo siguiente: "Esto agradó a nuestros antepasados, cuya sabiduría ojalá la llegásemos a igualar... Miran en gran peligro el que alguien aparezca, alguna vez, más sabio que nuestros antepasados...; pero si sobre alguna cuestión se puede decidir con criterios más acertados, debemos, aprovechando la ocasión, aferrarnos a ése, aunque sea con los dientes” (Moro, 2005, p. 13). Las cursivas son nuestras.

18 "Grande es el número de los nobles que ociosos, como zánganos, no solo viven del trabajo de los demás, sino que los esquilman como a colonos de sus fincas y los desuellan hasta la carne viva para aumentar sus rentas." (Moro, 2005, p. 15).

Las descripciones que hace Moro y Maquiavelo del ejercicio del poder en la Europa del momento son casi idénticas. La diferencia entre uno y otro está en que Maquiavelo promueve la permanencia y re-proyección de los modelos de gobierno propios de la tradición europea y propone un perfeccionamiento racional de sus principios, tácticas y estrategias. En dirección contraria, Moro propone la cesación de esos modelos y promueve la experimentación en la novedad. 
príncipes ${ }^{19}$ ambiciosos que buscan el dominio total del poder. En pocas palabras, la sociedad descrita por Nicolás Maquiavelo en El Príncipe y su propuesta de un orden basado en la repetición modélica de las formas políticas del pasado, en la invariabilidad de los principios que rigen lo humano y en el eterno retorno de los hechos pretéritos al presente. Del lado contrario están las posibilidades que ofrecen "los otros lugares" en el "nuevo mundo", hacia donde conduce la canoa a Hitlodeo y donde este encuentra mejores modelos de sociedad, cuya superioridad radica precisamente en que en ellos no existen las estructuras sociales europeas perpetuadas por la tradición ${ }^{20}$. Jalonado por esos modelos nuevos, descritos en las cartas de los navegantes, es que se construye el discurso de Utopía y se desplaza la cuestión de la necesidad desde el castigo divino a una discusión que puede ser ordenada por la política.

\section{Topía y U.Topía: El triunfo de la necesidad}

Tanto como la articulación utópica al relato del nuevo mundo ${ }^{21}$, es sabido que los elementos precolombinos que orientan la idea filosófica de la perfectibilidad del mundo social fueron eliminados violentamente de las comunidades concretas que funcionaban según esos principios. Es un hecho que las cartas y documentos que hablan del Paraíso o de la Edad de Oro y que ofrecen la materia para la inspiración de Utopía, entregan al mismo tiempo las orientaciones para montar la mayor y prolongada empresa de conquista, despojo y sometimiento conocida por la historia de la humanidad. De tal manera que siendo el mundo extra europeo precolombino la referencia concreta del imaginario utópico moderno, es transformado muy pronto en un espacio de catástrofe sociocultural a una escala sin precedentes. Este fenómeno se inicia en las primeras cartas de Colón, en el instante mismo en que en ellas se arrebata la libertad física y espiritual a los seres humanos y se los objetualiza como algo que se puede ofrecer y donar al rey y al papa ${ }^{22}$. Al primero bajo la condición de siervos y/o esclavos, al segundo bajo la condición de almas para su rebaño.

19 "En primer término, los príncipes mismos se ocupan con más gusto de los asuntos militares... que las artes de la buena paz; y más se preocupan de discurrir procedimientos para conquistar, lícita o ilícitamente, nuevos reinos, que de administrar bien los que poseen" (Moro, 2005, p. 12).

20 El vasallaje, por ejemplo. Hitlodeo rechaza en todos sus términos esta condición: “Considero, pues, que deben aquéllos estar contentos de mí y que no tienen ningún derecho a pedirme que para su beneficio, me convierta en siervo de ningún rey". (Moro, 2005, p. 11).

21 En Nueva Atlántida (1627) de Francis Bacon la expedición que arriba al lugar utópico parte del Perú. En La ciudad del sol (1623) de Tomaso de Campanella el discurso utópico es un Almirante Genovés.

22 Como bien se sabe, la documentación asociada a la apropiación de la otredad desconocida comienza con las Capitulaciones de Santa Fe, el contrato que firman los reyes católicos con Cristóbal Colón en abril, antes de que este emprenda el viaje de 1492. Ahí se establecen previamente todos los términos económicos y repartición de ganancias sobre lo desconocido: "Igual que de todas y cualquier mercadería, si son perlas, piedras preciosas, oro, plata, especies, del nombre y forma que sean, que se puedan comprar, trocar [cambiar a través del trueque], hallaran y estuvieren dentro de los límites de dicho Almirantazgo, que desde ahora Vuestras Altezas hacen merced [recompensa] al dicho don Cristóbal y quieren que vaya y lleve para si [a los reyes] la decena parte de todo ello, quitadas de las costas [...] y que vaya y tome una décima parte para sí mismo, y que haga de ello a su voluntad, quedando las otras nueve partes para Vuestras Altezas."

Recuperado de: http://www.culturandalucia.com/Cartas\%20de\%20Cristobal\%20Col\%C3\%B3n.htm 


\section{MARTÍNEZ}

Este acto de sometimiento, es inseparable de tres elementos de insondables consecuencias para el mundo americano de aquel entonces: la repentina territorialización del mundo como mercancía, la desacralización de la naturaleza como insumo para la explotación ${ }^{23}$ y la violenta transformación de seres humanos en propiedad privada. Como bien sabemos, estos tres elementos llevan la cuestión de la necesidad a su fase moderna y establecen el marco de la occidentalización americana.

La catástrofe sociocultural señalada tiene consecuencias que se relacionan con Utopía como propuesta política de la modernidad inicial. Para ver esa relación, lo primero a considerar es que con la desaparición de las sociedades a las cuales se refieren Colón y Vespucio desaparece la diferencia como horizonte real de posibilidad y en su lugar reinará una sola manera de concebir la organización social: la europea monárquica católica, cimentada en la propiedad privada y su acumulación a escala global. El asunto es que esos topos políticos desaparecieron de la historia dejando sin embargo un rastro importante en el pensamiento y la conciencia modernos como lo muestra Freud. Quedaron en el horizonte de la cultura bajo la condición del desplazamiento y retornaron a ella desalojados del acontecer histórico como u-topos, U-topía, como fenómenos políticos sin lugar. De tal manera que si ponemos la obra de Moro en la perspectiva histórica del siglo XVI americano y de la modernidad inicial, esta se nos presenta como el escenario en el cual la posibilidad de un mundo sin necesidad se transforma en huella, rastro y ruina discursiva. En este sentido, Utopía no es el anuncio de la sociedad que está por venir, a la que el ser humano podrá llegar alguna vez, sino el relato a contrapelo de la desaparición de una forma de sociedad que existió en el pasado inmediato, hasta el siglo XVI.

\section{Poesía y desdicha en el Reino de Chile}

Es un hecho notable que el europeo que llega al nuevo mundo no sufre ninguna transformación, ni en virtud de la bondad natural (Freud, 2006), ni en virtud de la bondad social que se le ofrecen a la experiencia (Moro, 2005). Al contrario, son muchos los casos en los cuales su impulso destructivo incrementa hasta dimensiones aberrantes lo que conocemos como "sufrimiento social" y re-produce en los otros lugares la conciencia de la desdicha.

La conquista del Reino de Chile es un buen ejemplo y para observar aquello bien vale reseñar los elementos dinamizadores de la empresa en general ${ }^{24}$ : i) el violento proceso impulsado en Sudamérica por la búsqueda delirante del oro que ofrecía la leyenda del Dorado y la notable descomposición moral que esa búsqueda produjo en las huestes cristianas; ii) los intereses geopolíticos imperiales, entre los que se cuenta la necesidad de controlar el

23 Paul Zumthor citando a Le Goff habla del paso de la "geografía de la nostalgia" a una "geografía del deseo", agresivo, conquistador y ávido de dominar el espacio. Zumthor, P. La medida del mundo. Madrid; Cátedra; 1994. p. 231. La documentación asociada a esta transformación tiene su antecedente en el Tratado de Alcáçovas (1479), luego se establece geopolíticamente con el Tratado de Tordesillas (1494) y se cierra en lo trascendente con las Bulas Alejandrinas (1493). Las partes involucradas son: la corona portuguesa, los reyes católicos y el papado español de Alejandro VI.

24 Carlos V, “Capitulación Real de Toledo”, emitida el 21 de mayo de 1529. 
comercio global mediante un emplazamiento terrestre en el Estrecho de Magallanes.

Con el oro y el comercio a la vista, esta conquista se piensa, gestiona y financia en un periodo en el cual los conquistadores ya tienen una amplia experiencia económica y militar en la organización, montaje y realización de la guerra fuera de Europa. Esto es, en el montaje de una empresa mixta privada-monárquica sumamente rentable, dirigida y ejecutada eficazmente por hijosdalgo segundones y por soldadesca de toda laya, pero soportada por grandes masas de indios esclavos o por esclavizar. En esta organización "empresarial", en el sentido de los siglos XVI y XVII, el rey cumple el rol de una lejana figura patrocinadora o franquicia legal, a la cual hay que entregar cada cierto tiempo sus utilidades -el quinto real- para contar con el marco legal -la "policía cristiana" y sus instrumentos- que permitía el desarrollo de todo el proceso. Sin mucho adorno ni grandes proyectos de evangelización, este es el contexto político-administrativo en que toma cuerpo la idea de avanzar por el continente hacia el estratégico Estrecho de Magallanes.

No obstante lo pragmático del asunto, en el Reino de Chile se produjo una serie de obras literarias notables tanto por su calidad poética como porque nos legaron valiosísima información sobre varios asuntos que nos interesan. Estos son: las organizaciones sociales de los otros lugares, las tensiones que sufre la conciencia europea al llegar a ellos, el desplazamiento del asunto bíblico de la necesidad al discurso poético moderno y la aparición escritura criolla chilena como una escritura del desastre.

La más famosa de esas obras es La Araucana (1574-1589), de Alonso de Ercilla, poema célebre por haber iniciado un ciclo en las letras hispánicas; por entregar una imagen heroica del pueblo mapuche en defensa de su libertad y de su tierra; y porque de él se desprende una dura crítica a los principios y valores que movían particularmente esta guerra de conquista. En este momento la obra de Ercilla resulta especialmente valiosa para nosotros, pues, al igual que Utopía, entrega una imagen vívida de la proyección de la conciencia desdichada del "explorador civilizado" europeo-católico sobre el "primitivo".

Lo primero a señalar en La Araucana es que el hablante lírico del poema sufre una transformación importante en el Canto XXXVI de la tercera parte de la obra, pues ahí deja de ser un soldado protagonista de una guerra sanguinaria, para convertirse en un marino explorador impulsado por el deseo de conocer, como Rafael Hitlodeo y los compañeros que lo acompañan en su viaje a Utopía. Segundo, que la imagen del encuentro con el "primitivo" se produce en parajes a los cuales no había llegado antes ninguna avanzada europea y se desarrolla en medio de una naturaleza que evoca los paisajes benignos de la Edad de Oro de la humanidad:

Quien muchas tierras vee, vee muchas cosas

que las juzga por fabulosas la gente;

y tanto cuanto son maravillosas

el que menos las cuenta es más prudente; 
y aunque es bien que se callen las dudosas

y no ponerme en riesgo así evidente

digo que la verdad hallé en el suelo

por más que afirmen que es subida al cielo.

\section{Estaba retirada en esta parte}

de todas nuestras tierras excluida, que la falsa cautela, engaño y arte

aún nunca habían hallado aquí acogida;

(...) (Ercilla, p. 220).

En esta escena la visión de la tierra maravillosa está ligada a una verdad que el sujeto encuentra más allá del "decir prudente"; o sea, más allá y en contra del sentido común, el saber y la creencia de la época. Por esta razón la conciencia enunciante de la obra incorpora la función testimonial y esgrime el criterio de verdad de ese periodo (el testigo de vista, "el que mucho vee") para atajar de antemano el desvío metafísico o la deriva ficcional que hará la gente de esa verdad. La verdad imprudente es que esa tierra maravillosa está en el mundo y en la historia ("la verdad hallé en el suelo"), no en el cielo filosófico o teológico, ni en la fábula. Pero se encuentra en un espacio externo, excluido de la geografía que el "explorador civilizado" conoce y concibe como suya desde el Génesis hasta ese momento. Esta exclusión es geográfica, moral y espiritual a la vez, circunstancia a la cual se debe que no haya llegado nunca hasta ahí la falsa cautela, engaño y arte, en suma, la astucia, la artimaña, el mal. En términos espaciales, el episodio que ahí se inaugura hace referencia a una naturaleza fertilísima, pródiga, generosa con el ser humano, en donde los nativos no padecen necesidad y adonde el europeo llega para calmar hambre y consolar penurias: la naturaleza de la Edad de Oro o edénica, ajena al devenir histórico de la caída, la expulsión y el relato del padecimiento. En términos bíblicos, la escena se desarrolla en un espacio natural y cultural en el cual el castigo divino no ha roto la amistad entre el hombre y la naturaleza.

Adversa a la opinión de Freud (2006), pero en acuerdo con Utopía (2005), la generosidad natural se expresa como bondad moral y elevación de espíritu en los sujetos que habitan las islas a las que llegan Ercilla y sus compañeros. De acuerdo a esta correspondencia se describe al "primitivo", quien resulta ser un "gallardo mancebo floreciente", "gracioso" y bien "dispuesto", "expedito en término y lenguaje", vestido con "manto y floja túnica", que saluda "cortés y alegremente", "en lengua extraña", a los hambrientos y desastrados extranjeros. La larga descripción del este joven, su franca inteligencia, entereza moral y gracia física, configuran la imagen de un sujeto poético en todos sus aspectos, de tal manera que proyecta la generosidad, templanza y sabiduría naturales del hombre incorrupto de la Edad primera de la humanidad. A su cargo está un notable discurso de bienvenida en el que 
deja al libre albedrío del europeo escoger entre la paz o la guerra para entrar en esas islas, invitándolo primero a tomar el camino de la amistad sincera que se le brinda.

Terminado el discurso, aparecen, como en Utopía, las naves americanas, en este caso colmadas de alimentos y vituallas para remediar las necesidades de los conquistadores desvalidos:

No estaba nuestro campo aun asentado,

ni puesta en lugar las demás cosas, cuando de aquella parte y deste lado hendiendo por las aguas espumosas, cargadas de maíz, fruta y pescado arribaron piraguas presurosas refrescando la gente desvalida, sin rescate, sin cuenta ni medida (p. 220).

La generosidad del "primitivo" sin rescate, sin cuenta ni medida (sin prenda, sin cobro, desmedida) produce ahora sí la escena que Freud recuperará siglos más tarde a su manera, en la que el "explorador civilizado" experimenta con plena lucidez la hondura de su desdicha y un irremediable malestar hacia su propia cultura, tal como le sucede a Rafael Hitlodeo cuando abandona las naves de Américo Vespucio y se adentra en las sociedades no europeas. La diferencia entre Hitlodeo y el hablante lírico de La Araucana es que este último sí llega a conocer la raíz de su desdicha, cuando reconoce ser partícipe de la destrucción de esas sencillas y felices formas de vida:

La sencilla bondad y la caricia de la sencilla gente de estas tierras daban bien a entender que la cudicia aún no había penetrado aquellas sierras; ni la maldad, el robo y la injusticia (alimento ordinario de las guerras) entrada en esta parte había hallado ni la ley natural inficionado.

Pero luego nosotros, destruyendo todo lo que tocamos de pasada con la usada insolencia el paso abriendo les dimos lugar ancho y ancha entrada; y la antigua costumbre corrompiendo, de los nuevos insultos estragada, 


\section{MARTÍNEZ}

\section{plantó aquí la codicia su estandarte}

con más seguridad que en otra parte (p. 220).

Una revisión no muy exhaustiva del proceso histórico desarrollado en el nuevo mundo global, pronto deja claro que los principios utópicos no prosperaron en Europa, menos aún en el continente Americano devastado por la codicia, como se confiesa en el poema. Aunque aquí y allá el modelo social que triunfó fue aquel descrito con negros tientes en Utopía y de manera positiva en El príncipe (1532), también es cierto que las visiones de las sociedades evocadoras de la legendaria Edad de Oro y/o el Jardín del Edén, no dejaron de tensionar el desenvolvimiento de la modernidad.

En el Reino de Chile esa tensión se agudiza en el siglo XVII de su modernidad temprana, con el enfrentamiento del mundo indígena y el mundo hispanizado, compuestos por mapuches de un lado y del otro por españoles y criollos cristianos y por mestizos con distintos niveles de cristianización. En esta perspectiva, quizá uno de los libros donde se plasman mejor esas tensiones y se describe el mundo degradado de la modernidad colonial es Cautiverio, feliz, Del Maestre de Campo General Don Francisco Nuñes de Pineda. Y rason Individual, de las Guerras Dilatadas, del Reyno, de Chille. Compuesto Por el mismo. $Y$ dedicado Al Rey Nuestro Señor, Don Carlos, Segundo que Dios guarde muchos años para gloria Nuestra (Núñez de Pineda y Bascuñán, 1673). Asimismo, es una de las obras en que se autorretrata mejor la conciencia desdichada cuando esta se criolliza, y se debate entre el profundo malestar que le ocasiona la cultura hispano-católica virreinal y la admiración que le inspira su enemigo, el "primitivo", guerrero o cacique, perteneciente al ejército y al sistema de gobierno de la nación mapuche y habitante de un mundo que todavía no ha sido arrasado por la cuestión de la necesidad.

Aun cuando Cautiverio Feliz... es, como decimos, una obra escrita por un militar criollo del ejercito de su majestad, hijo de encomendero español, que reclama la restitución de los beneficios y encomiendas que, según él, le pertenecen en derecho por la participación de su padre y la suya propia en la guerra de conquista, la exposición de la causas del conflicto hispano/mapuche hacen de este libro una de las obras políticas (Correa, 1965) más críticas de la cultura virreinal del siglo XVII y de más lúcida conciencia ante la ruina producida por esta en el mundo indígena moderno.

Si bien el contenido político es lo que generalmente lleva a la obra de Núñez de Pineda y Bascuñán, no es el único elemento que queremos observar en relación con las otras obras que hemos comentado. Particularmente nos interesa anotar que en la obra del criollo la escena crítica guarda la misma configuración, sigue los mismos pasos y despliega los mecanismos reflejos que hemos visto en Utopía y La Araucana. Tal como en ellas, en Cautiverio feliz... el sujeto emprende un viaje hacia el otro lugar. En este caso, ese desplazamiento significa traspasar la frontera bélica y política que divide el mundo hispánico del mundo mapuche e instalarse en este último en la condición no feliz de prisionero. A pesar de que la mudanza 
al territorio del enemigo es forzada, cuando el sujeto "civilizado" hispánico-católico conoce de cerca la sociedad del "primitivo", sus formas sencillas de vida, sus valores espirituales y sociales, su generosidad y gentileza de trato, la integridad de sus gobernantes, el amor familiar, el trabajo comunitario para la producción de alimentos y bienes, el amor a su tierra y cultura, incluso su caridad con el otro enemigo ${ }^{25}$, es que se produce en él el estado anímico que da lugar a la felicidad paradojal en el cautiverio. En este punto, Cautiverio feliz... sigue el mismo patrón de Utopía, de La Araucana y de la escena freudiana de $E l$ malestar en la cultura, pues el contacto con la felicidad del Otro hace que el sujeto vuelva la mirada hacia su propia cultura y vea en ella la fuente de la infelicidad social, la promoción de la violencia y las causas políticas y religiosas de la ruina de este reino, suscitándose en él el mismo malestar que sienten Hitlodeo y Ercilla, y que Freud describe en su famoso ensayo:

Quedemos con la historia en caza de este casique, adonde por algunos días habré de tener mi asistencia forzosa, y ponderemos un rato la costumbre de estos naturales, supuesto que el principal blanco a que se encamina es a sacar de ella algunas consecuencias ajustadas al principal intento a que este libro se endereza, de la felisidad y dicha que tuve en mi cautiverio, y de la dilación de guerra tan antigua como la de Chile, para confusión de nuestro gobierno, como causa principal de sus ruinas (p. 537).

La "felisidad" y la ruina, la "felisidad" y la guerra, en suma, configuran el asunto del libro y la tensión que lo recorre, pues así como en el plano del discurso histórico configuran el conflicto entre los dos mundos, asimismo en el plano de la subjetividad origina la irresoluble desdicha de la naciente identidad hispánica criolla del Reino de Chile traspasada por la necesidad. Tal como Utopía, Cautiverio feliz... muestra una sociedad máximamente menoscabada, un cuerpo social enfermo, al borde de la muerte en su fundación. Por eso en ambas obras una conciencia lúcida y desposeída a la vez da cuenta de la guerra y de la dominación colonizadoras como los dispositivos teológico-políticos más eficientes de la codicia imperial y virreinal, asimismo eficaces para traspasar allende los mares un sistema moralmente corrupto y voraz en el ámbito material y en el espiritual:

Yo juzgué verdaderamente que solo en este reino, por remoto y apartado del sol universal que esclarece y vivifica toda nuestra monarquía, se acostumbraba este abuso contagioso, y es común opinión que de otros más inmediatos tribunales y palacios viene derivada esta perversa ley, con que el achaque es de muerte y la enfermedad

25 Son varios los relatos en la obra en los cuales se muestra el buen trato y el respeto con que son tenidos en el mundo mapuche los prisioneros españoles. Esto contrasta con los malos tratos, esclavización, desfiguraciones del rostro, mutilaciones y violaciones a los que son sometidos los prisioneros y prisioneras mapuches en el mundo hispánico chileno. 


\section{MARTÍNEZ}

incurable, porque proviene de la cabeza el mal, y así no hay que maravillarnos que los inferiores ministros y tribunales caminen al paso de los mayores, siendo las normas y el régimen de los que se hallan en inferior jerarquía (p. 539).

Todo Cautiverio Feliz..., de principio a fin, es una obra que parece escrita para confirmar en el siglo XVII la dolorosa confesión que hizo el cristiano Alonso de Ercilla en el siglo XVI: Pero luego nosotros, destruyendo/ todo lo que tocamos de pasada... Esta comprobación, por supuesto, acrecienta el malestar del cristiano criollo hasta un punto que su estado anímico alcanza la dimensión de una verdadera devastación espiritual, pues reflejada en el espejo del "primitivo", la cristiandad se revela en el siglo XVII como una fuerza expansiva que sigue “... la antigua costumbre corrompiendo", como ya le dijo Ercilla al monarca. Confrontados entonces ambos bandos, la civilidad cristiana versus la civilidad regida por la ley natural, no cabe duda que el mal se encuentra en el primero de estos proyectos civilizatorios:

\section{“AL LECTOR}

Habiendo trabajado algunos meses y días, pío lector, en la historia de mi feliz cautiverio con intención fervorosa de manifestar y dar a entender las causas y fundamentos que se hayan para que esta guerra de Chile sea inacabable y perpetua, por las ciertas noticias que adquirí cuidadoso, estando preso y cautivo entre los indios antiguos, nacidos y criados en aquellos tiempos que principiaron esta conquista nuestros antepasados españoles, y por las experiencias largas que más de cuarenta años efectivos de estas fronteras de guerra me han participado, en cuyo tiempo con atención curiosa he reconocido la dolencia y el lastimoso achaque de que se halla no poco lastimado nuestro afligido reino; $y$, porque cada día en peor estado veo sus ruinas, originadas de los estilos de gobierno que algunos superiores ministros del rey, nuestro señor, han introducido, no tan solamente en este reino de Chile, sino es también en todas estas austriales indias..." (p. 73).

Para concluir este trabajo nos proponemos observar ahora la expansión de la geografía de la desdicha sobre el nuevo mundo y las consecuencias que eso tuvo en la configuración de la conciencia moderna americana. En este punto Cautiverio feliz... entrega imágenes que informan sobre la relación entre cultura y naturaleza; también muestra los vínculos entre naturaleza, necesidad y castigo que se tienen o no a ambos lados de la frontera. Del lado mapuche siempre se presenta un mundo con una intensa vida social que se manifiesta en juntas, reuniones, vistas, fiestas, etc. Todos estos eventos, desde los más íntimos de la vida familiar hasta los que involucran varias comunidades, se desarrollan alrededor de un banquete bien servido, abundante y variado, carnes, pescados, mariscos, chicha, frutas y "viandas muy gustosas" (p. 90), de tal índole que en ningún momento, ni en lo cotidiano, ni en lo festivo, se advierte en ese mundo algún atisbo de necesidad. Al contrario, 
la generosidad de la naturaleza es vivida por el "primitivo" con pleno disfrute, de la misma manera que entabla una gozosa afinidad con los elementos naturales y el clima. Con el agua, por ejemplo, mantiene una relación doméstica y "festiva”, íntima y comunitaria a la vez, que puede comenzar con un baño diario, salutífero, en las aguas heladísimas de ríos y lagos, y puede terminar con grandes celebraciones bajo la lluvia tempestuosa. Precisamente en una escena como esta, entre muchas otras, podemos observar las diferentes percepciones de la naturaleza que tienen el sujeto "civilizado" y el "primitivo"; asimismo, la disyunción entre la geografía de la desdicha y la geografía gozosa. Mientras que para el primero el clima, el agua y las estaciones tienen condiciones "penosas", para el segundo, tienen exactamente una condición opuesta:

Llegamos al concurso jovial el aplazado día, donde fuimos recibidos a su usanza con notable grandeza; y, como el tiempo era el más riguroso del año, por el invierno -que lo es en aquellas provincias penoso y destemplado-, aquella noche nos convidaron los caciques a que nos recogiésemos a los ranchos, porque no estuviésemos a la inclemencia de una noche tenebrosa, con agua y viento entreverada, como los demás de la plebe, que tienen por gusto y entretenimiento estarse días y noches cantando, bailando, comiendo y bebiendo, en medio de las lluvias más continuas (p. 90).

En esta escena podemos ver que lo que el "civilizado" percibe como hostil, tenebroso y adverso o como fuente de sufrimiento, según Freud, el "primitivo", por el contrario, lo incorpora gozosamente a su vida social. Por supuesto que esto marca una diferencia sustancial entre uno y otro, así como una manera de estar en el mundo y en la naturaleza de muy distinto signo. El "primitivo" no le teme al agua, al viento ni a la tormenta, no percibe los elementos como un límite para su vida social o como algo ante lo cual deba resguardarse, en cambio el "civilizado" sí, presiente en ellos una amenaza. De tal suerte que en este pasaje la conciencia criolla-hispánica muestra su íntima afinidad con la idea de la naturaleza como lugar del infortunio, en correspondencia con la convicción de habitar un orden social infausto, injusto y corrupto. Lo uno recae en lo otro en el orden de la historia, y ambas dimensiones se funden y performan la conciencia del criollo, su recóndito malestar. Por eso no resulta extraño que hacia el final el enunciante de la obra retome el relato del Génesis y termine invocando a la naturaleza para que inflija el castigo supremo que se merece la cristiandad en el nuevo mundo:

Son bastantes estos presagios para que yo pueda decir que es inacabable esta sangrienta y prolija guerra, y que este reino miserable se ha de ver hecho bosque tenebroso, porque echan leña en él los superiores, jueces y ministros; $y$ ha de igualar el mar sus soberbias y vanas hinchazones, porque echan agua en él que abunde y rebose y a todos nos consuma y nos sepulte (p. 947). 


\section{CONCLUSIONES}

Al final de este trabajo hemos visto cómo "la noticia del nuevo mundo" y el contacto del europeo con las sociedades indígenas o "primitivas”, según Freud, tensionaron de manera inédita la cuestión de la necesidad e influyeron decisivamente en su migración desde el discurso religioso hacia la filosofía, la política, la poesía y el relato autobiográfico vinculado a la reflexión histórica. Esa migración es tan notoria y significativa que bien podemos concluir que constituye una de las marcas históricas de la modernidad y de la conciencia moderna establecidas ambas en Utopía y en relación con el proceso de occidentalización americana. Tal como muestra Ercilla cuando relata su participación en la conquista de Chile, en este proceso el sujeto europeo-cristiano va descubriendo que ni la desdicha ni la instalación de la necesidad como horizonte de la vida humana y social son producto de una acción adversa de la divinidad sobre los hombres, sino el resultado de su propio hacer histórico sobre la realidad y sobre los Otros.

Bien podemos decir que el descubrimiento de Ercilla coloca al Reino de Chile en un lugar significativo en la historia de la necesidad y en la de la conciencia moderna transida en su origen por el sentimiento del malestar. Del siglo XVI al XVII, de la representación del Jardín del Edén a la del territorio arruinado por la guerra, se desarrolla todo un acontecer histórico en el cual los protagonistas ya no son exclusivamente europeos. En ese trayecto el Reino de Chile también es especialmente relevante en lo que dice relación con la emergencia de una conciencia de la desdicha criolla y con la percepción de habitar en un mundo trastocado en su origen por las penurias derivadas de la conquista material y espiritual europeo-católica. “El lastimado Chile” de Francisco Núñez de Pineda y Bascuñán, es mundo arruinado que se define y caracteriza en contraste con el del "primitivo", tal como señala Freud. Aun cuando se trata del mundo del "primitivo enemigo", este mundo resulta ser un lugar en el cual todavía priman ciertos valores que tienden a la felicidad social.

Solo queda por agregar que desde Utopía hasta Cautiverio Feliz todos los antihéroes u-tópicos exhiben una conciencia plenamente moderna, en antagonismo con su universo cultural, que asumen la escritura como un recurso para tramitar el malestar que los aqueja y para gestionar cierta coherencia poética-política al desastre de la conquista. Es decir, para hacer legible ese desastre y lo convertirlo en historia.

\section{REFERENCIAS}

Columbus, C. (1982). Textos y documentos completos. Relaciones de viajes, cartas y memoriales. Edición, prólogo y notas de Consuelo Varela. Madrid: Alianza Editorial.

Correa Bello, S. (1965). El Cautiverio Feliz en la vida política chilena del siglo XVII. Santiago: Editorial Andrés Bello.

De Certeau, M. (2003). Historia y Psicoanálisis. México: Universidad Iberoamericana Ercilla A. 
La Araucana. Santiago: Editorial del Pacífico. s/f.

Freud, S. (2006). El malestar en la cultura. España: Alianza Editorial.

Hopenhayn, M. (2005). Utopías del Renacimiento: Moro/Campanella/Bacon. México: Fondo de Cultura Económica.

Maquiavelo, N. (2005). El Príncipe. Traducción de Sergio Albano. Buenos Aires: Cuadrata.

Núñez de Pineda \& Bascuñán, F. (1673). Cautiverio Feliz.

Gruzinski, S. (2010). Las cuatro partes del mundo. Historia de una mundialización. México: Fondo de Cultura Económica.

Pastor, B. (1999). El jardín y el peregrino. México: Coordinación de difusión cultural UNAM.

Vespucio A. (2015). El Nuevo Mundo Los viajes de Amérigo Vespucci (1497-1504). Traducción, introducción y notas de Jean-Paul Duviols. Estados Unidos Stockcero.

Weinberg, S. (2016). Explicar el mundo. Buenos Aires: Taurus.

Zumthor, P. (1994). La medida del mundo. Madrid: Cátedra. 
